\title{
An intelligent hammer: a novel concept for automating nail and pile driving
}

\author{
S Ilanko \\ Department of Mechanical Engineering, University of Canterbury, Christchurch, New Zealand
}

The manuscript was received on 6 September 2004 and was accepted after revision for publication on 19 October 2004.

DOI: 10.1243/095440605X8360

\section{INTRODUCTION}

Some interesting novel ideas on how the compliance needs of manipulators may be met by changing the stiffness of a structure have been presented in a paper by Ang and Andeen [1]. The purpose of the present note is to outline a novel concept for another variable-stiffness mechanism that may be useful in automating the process of driving nails or piles.

It is common knowledge that, when manually hammering a nail into wood, care must be exercised not to use excessive impact energy. Starting with a smaller than necessary impact based on judgement, the impact would normally be increased until a satisfactory rate of penetration is achieved. Therefore, to automate the process of nail driving, the appropriate level of impact loading needs to be determined. However, this may vary significantly owing to the variability in the strength and penetration resistance of wood and the properties of the nail. While very few articles dealing with research into cracks caused by nailing are available in the literature $[2,3]$ (the present author has read the abstracts only as the articles are in Japanese), the author could not find any work on attempts to minimize such damage. Soft thin wood requires only an impact of small magnitude, and extra impact may damage the wood and/or the nail. On the other hand, thick hard wood may require a very large impact to penetrate the wood. There is a similar problem in driving piles in soil. The soil disturbance due to pile driving has been the subject of several recent papers $[4-8]$. Since soil strength and resistance vary considerably, the impact energy needed to drive a pile without causing soil disturbance is difficult to predict.

\section{CONCEPT}

The idea of varying structural stiffness to meet the compliance needs of manipulators can be extended to automate the process of hammering a nail or driving a pile. In these cases the impact loading may be controlled if the mechanisms used can sense the force induced and adapt to produce an optimum stiffness. One mechanism that may fulfil this requirement is shown in Fig. 1.

A variable-stiffness rectangular frame consists of a rigid U-frame (A) and a detachable flexible beam (B) which carries the hammerhead (C). Several restraining struts (D) which can prevent the displacement of the flexible arm are screwed into the top part of the U-frame. The U-frame is attached to a driving rod (E) which may be controlled by a robot. Each time the machine is operated, the frame would be subject to an impact loading providing sufficient energy to be transferred onto the hammerhead to drive the nail into a workpiece offering the stiffest resistance to penetration. However, the mechanism proposed would allow just the right amount of energy to be imparted onto the hammerhead so that the nail would penetrate a workpiece. This is achieved by controlling the force transmitted to the nail. A shock absorber (F) should be used to absorb any residual energy as soon as the nail is fully driven into the workpiece.

For a given impact energy, the contact force that develops between the nail and the hammer depends on the resistance to penetration. If the workpiece consists of soft wood or packaging material offering little resistance, it would be subject only to a small force corresponding to the maximum internal force that could be induced in the beam, as shown in Fig. 2a. With increasing resistance to penetration, the force required to drive the nail would increase. The beam would initially bend to some extent, but at some stage the deflected beam would contact two struts (Fig. 2b). Thereafter, the driving arm behaves like a clamped beam with intermediate supports offering increased stiffness, thus exerting more force on the nail. Depending on the properties of the workpiece, more struts may also come into contact with the beam; when nailing hard wood, the beam would become very stiff, as shown in Fig. 2c. The force induced at the hammerhead is proportional to the corresponding beam stiffness. 
(E)

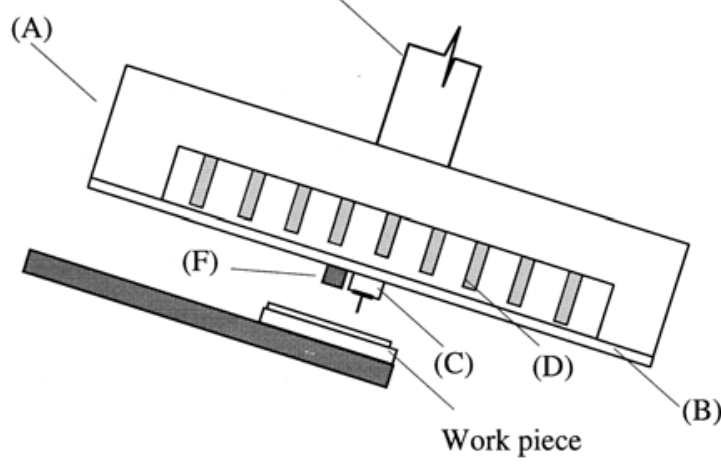

Fig. 1

Therefore, the stiff beam configuration would allow more force to be delivered to the nail.

The object of the design is to ensure that, as the hammer hits the nail, only some of the impact energy is allowed to be absorbed by the nail and workpiece, and the hammerhead comes to a halt as soon as the nail is driven fully. The magnitude of the energy absorbed by the hammer is determined

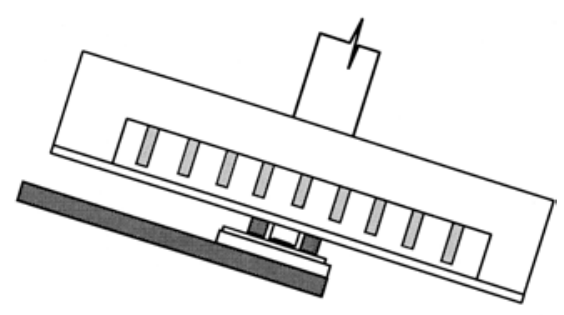

(a)

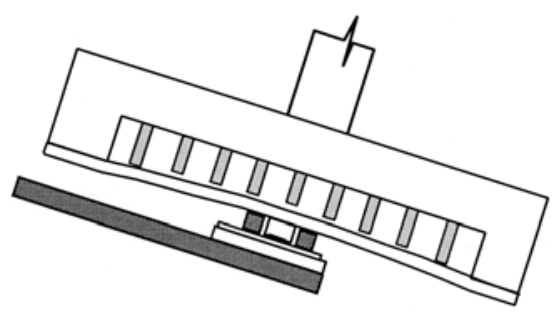

(b)

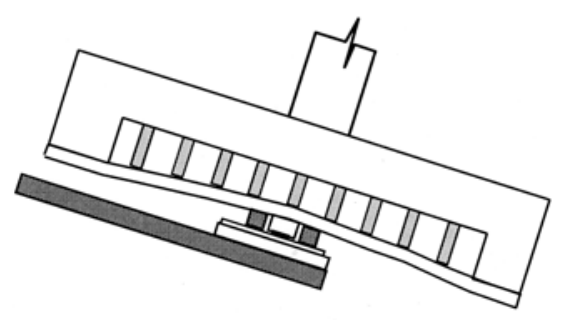

(c)

Fig. 2 by the force required to cause penetration of the nail. By permitting the stiffness of the hammer to vary, the amount of energy imparted on the nail and workpiece may be adjusted. For optimum design, the change in the stiffness of the beam must be such that the remainder of the energy is absorbed by the U-frame and the absorber without causing any deformation of the wood. The stiffness of the beam at any stage depends on its flexural rigidity and the position of the restraining struts.

\section{DESIGN CONSIDERATIONS}

In order to carry out a design and build a prototype for testing, the following considerations arise. Firstly, the method of applying the impact load needs to be decided. To deliver a constant amount of impact energy, if the hammering action can be done vertically, the U-frame could be picked up by an electromagnet and dropped from a fixed height. Alternatively, the impact may be provided pneumatically. Initially, as a preliminary study, the frame could be manually dropped from various heights. A beam with a rectangular cross-section may be used, but its dimensions, together with the dimensions of the U-frame, have to be determined. Estimates of impact loading from hand-operated hammers may be used for this purpose. The size and location of the struts and their profile and fixing arrangements depend on the force to which they would be subjected and the desired profile of the beam when it is used to drive nails on workpieces that offer the highest resistance. In exploratory research, the struts could be screwed in so that the profile could be easily adjusted. However, in selecting the type of fixing arrangement in the final design, it is better to avoid screws as they would be subject to repeated impact loadings. In the final design, the struts could be replaced with a rigid plate having a curved surface profile at the bottom, as shown in Fig. 3.

\section{CONCLUDING REMARKS}

The impact force that is necessary to hammer nails into wood varies depending on the type of wood

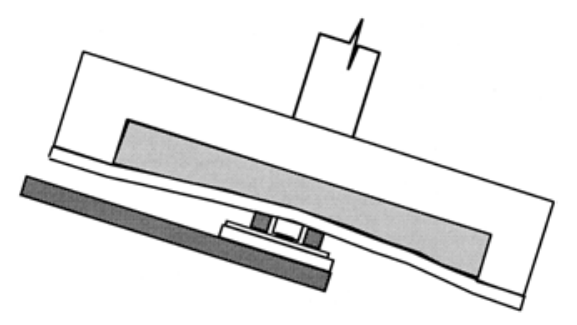

Fig. 3 
and the thickness of the workpiece. A concept for a mechanism that adapts its stiffness according to the force induced at the hammerhead has been proposed. This mechanism may prove to be useful in delivering the correct amount of impact energy to the hammerhead to drive nails into wooden workpieces and could also lead to the design of intelligent pile-driving mechanisms. This may be a suitable topic for exploratory research as a student project or design assignment.

\section{ACKNOWLEDGEMENT}

The idea for this project occurred following a seminar by Dr Gerry B. Andeen, formerly at SRI International, Menlo Park, California, in which he mentioned the difficulties in automating the process of nailing in the packaging industry. The author would also like to thank Dr Volker Schlegel, Department of Mechanics and Ocean Engineering, Technical University of Hamburg-Harburg, Germany, for suggesting another potential use for such a system in driving piles, and his colleagues Dr Sivapatham Naguleswaran, for suggesting the alternative system in Fig. 3, and Emeritus Professor Harry McCallion, for suggesting a suitable location for the absorber.

\section{REFERENCES}

1 Ang, M. H. and Andeen, G. B. Specifying and achieving passive compliance based on manipulator structure. IEEE Trans. Robotics and Automn, 1995, 11(4), 504-515.

2 Tokuda, M. Qualitative measurement by soft-X-ray of crack formation in wood as a result of nailing. 1: effects of nailing methods and configuration of nails. Mokuzai Gakkaishi, 1994, 40(2), 119-126.

3 Tokuda, M. Qualitative measurement by soft-X-ray of crack formation in wood as a result of nailing. 2: effects of nailing wood factors on the crack size. Mokuzai Gakkaishi, 1997, 43(10), 832-838.

4 Thandavamoorthy, T. S. Piling in fine and medium sand - a case study of ground and pile vibration. Soil Dynamics and Earthquake Engng, 2004, 24(4), 295-304.

5 Bozozuk, M., Fellenius, B. H., and Samson, L. Soil disturbance from pile driving in sensitive clay. Can. Geotech. J., 15(3), 346-361.

6 Iskander, M. G., Olson, R. E., and Bay, J. A. Design and performance of an electropneumatic pile hammer for laboratory applications. Geotech. Testing J., 2001, 24(1), $72-82$.

7 Choe, J. and Juvkam-Wold, H. C. Pile driving analysis for top hammering and bottom hammering. J. Geotech. and Geoenviron. Engng, 2002, 128(2), 174-182.

8 Hwang, J. H., Liang, N., and Chen, C. H. Ground response during pile driving. J. Geotech. and Geoenviron. Engng, 2001, 127(11), 939-949. 
Copyright of Proceedings of the Institution of Mechanical Engineers -- Part C -Journal of Mechanical Engineering Science is the property of Professional Engineering Publishing and its content may not be copied or emailed to multiple sites or posted to a listserv without the copyright holder's express written permission. However, users may print, download, or email articles for individual use. 